\title{
Method for Image Processing
}

\author{
Lenar Ajratovich Galiullin', Rustam Asgatovich Valiev ${ }^{2}$ \\ ${ }^{1}$ PhD, Associate Professor, Kazan Federal University, ID Scopus: 39361435200 , \\ ORCID: 0000-0001-8640-1734, \\ ${ }^{2} \mathrm{PhD}$, Head of the Department of Information Systems, Kazan Federal University, Russia. \\ ID Scopus: 7103235085, ORCID: 0000-0002-2589-6208,
}

\begin{abstract}
The goal of the article was to increase the efficiency of the laser complex by aggregating various processing methods into one working tool and developing a new software firmware for the machine. A detailed analysis of the enterprise and the platform for which it is required to develop a project was carried out. Thus, alternative solutions in the form of third-party graphic editors, various applications for controlling a laser machine, as well as software firmware for control cards were considered. Analysis of third-party solutions made it possible to look at the problem from different angles, identify and clarify the necessary precedents and possible solutions. The result of this chapter was the development of requirements for the designed system. The architecture of the software firmware of the machine was developed and the methods of image processing were determined, the principles of their operation were considered, block diagrams were implemented. The functionality of software firmware was described, an example of working with a computer on a parallel port is shown. They also described in detail the implemented image processing methods, and provide arguments for choosing one or another of the methods. At the end of the chapter were presented examples of the program, as well as highlighted the main advantages of the algorithms.
\end{abstract}

Keywords: Image, Method, Processing, System, Automation

\section{INTRODUCTION}

Laser engraving is a modern method of applying patterns [1], images and texts to various surfaces. Powerful narrowly focused laser radiation is used to create appropriate drawings or inscriptions.

Recently, interest in laser engraving of surfaces has had a significant increase. This is due, not least, to lower prices for components and platforms for assembling their own workstations and the development of technologies [2]. Modern technologies significantly increase the parameters of engraved products, which undoubtedly attracts both ordinary users and companies that build their business on laser engraving.

However, if a large software complex already exists for large companies, such a complex is not profitable for small business and private production, and therefore there are some limitations: there is not enough specialized software for controlling the machine, as well as free software that allows you to process images, preparing them as much as possible to print on a laser engraver [3].

Not all images are suitable for laser engraving. Therefore, there are problems with image processing in various graphic editors, which do not always allow us to solve the whole range of required tasks. Against this background, users of laser machines need to work in stages in various editors [4].

Laser equipment is in great demand and is purchased not only for industrial production, but also for home use. This is due to the very high quality indicators of the products obtained, speed and ease of use [5]. The last point is directly related to the fact that this process is automated and a person practically does not participate in machine control.

However, a fully automated system and a powerful machine are expensive, so the company bought parts and hired technicians to build their own inexpensive machine.

In order for the machine to understand what needs to be done, a graphic editor is required and a graphic image is prepared in a format suitable for the machine [6]. Quite expensive devices have on board software that supports a huge number of formats, but for the mass user, machines are often available only with the ability to print common image formats and therefore the company uses non-core graphic editors.

To recognize the layout created in the graphics editor, was recognized and reproduced on the material, requires a special layer between the machine and the computer. The company uses a self-written application to interpret the prepared image into the command stream to the Arduino control board installed in the machine. This firmware is responsible for the movement of stepper motors, directing the laser head to the desired position, and controls the burning of the surface.

\section{METHODS}

For professional machines, many specialized graphic editors are used. They have great functionality, stable fast operation, but with all their advantages they are expensive and not suitable for small organizations in view of their unprofitability. 
According to the reputable publisher INFOLASER, Adobe Illustrator is a graphic editor that can handle cutting mockups for any software-controlled equipment, including a laser machine. The program has a huge number of libraries and tools that allow you to create an image of any complexity and detail.

In addition, it provides the ability to work with the machine through a dialog box in which you can configure work parameters such as width and depth of engraving and cutting, specify the material, its thickness and other parameters.

CorelDraw is a software package that is not inferior to Adobe Illustrator in terms of popularity or functionality. It allows you to convert raster images (for example, photographs) into vector ones, create curvilinear contours, has a lot of ready-made templates and the most understandable interface, so work in CorelDraw can be done even by amateurs. Among a large number of formats for saving the finished model there are, including those that are required to create a control program for the laser machine;

LibreCAD - software for working with flat images. Very easy to learn, with a large set of tools and extensive functionality. This software is not as well known as the two aforementioned, but quite popular among narrow circles of developers of layouts for laser processing.

Of the above editors, LibreCAD is more suitable for small companies because of the free and openness of its platform, because Adobe Illustrator and CorelDraw cost significant money for a subscription. But he is not without his flaws due to the lack of some functions.

LaserCut is a software shell with an intuitive interface that allows you to automatically place blanks on a sheet, control the movement of the cutting head, adjust the parameters of the speed of the beam, its power, cutting depth and visualize all stages of work. Of the minuses of this solution: it is delivered under branded machines of high power.

LaserWork is another common program for controlling laser equipment. It is distinguished by its wide functional capabilities and multitasking, in particular, it allows you to find out the end time of the task, set the coordinates of the start of cutting and the end point, adjust the laser route during the movement, adjust the beam operation modes, control the rotary device if necessary, and much more.

"GRBL Controller" is the most popular program for translating control sequences into a GRBL machine.

Advantages: free, multi-platform (Windows, Linux), easy to learn and use, has elements of visualization of the control path

Disadvantages: the latest version was developed for GRBL 0.9 , does not work correctly with the settings \$ s GRBL 1.1, does not perceive the "soft borders" of the working area of the machine.

Expensive equipment comes with its own closed control systems, so there is no way to evaluate their internal content. However, since cheap machines based on Arduino boards are popular, we can single out GRBL firmware for these boards.

Grbl is an uncompromising, high-performance, low-cost alternative to parallel port controllers for milling machines. Grbl runs on an Arduino platform based on a 328p processor (Uno, Duemilanove, Nano, Micro, etc.). This allows you to assemble your own laser machines with little finance, you can take the library without it on the Internet, and it gives significantly more features than other firmware. But to work through this mechanism, you need to deal with the initial setup.

\section{RESULTS AND DISCUSSION}

The development of the project is based on the hardware of the machine, so it necessarily requires special attention. She is the platform Arduino Uno, reference books [7] and [8], with an additional module of stepper motors, reference [9]. The choice of this platform was based on simplicity, accessibility in retail and a huge base of both modules for assembly and software that are easily integrated into the Arduino IDE's own development environment [10]. It is free and distributed from the official website of the company.

Thanks to this choice, the development of the microcontroller firmware on the board is carried out in $\mathrm{C} / \mathrm{C}$ $++[10]$ with minor changes for the platform, after which it is compiled using avr-gcc. Development does not require learning a specific programming language, and most problems when describing algorithms have a standard solution. Therefore, this choice together reduces the relative complexity of the development.

The resulting device is based on the following elements:

a) Arduino UNO;

b) em-210 stepper motors with 48 steps per revolution;

c) $500 \mathrm{~mW}$ laser;

d) power supply for $12 \mathrm{v} 1 \mathrm{~A}$;

d) DRV8825 drivers with a shield for placing CNC SHeeld v3.

As part of this hardware platform is the firmware of the board and software for image conversion. They cover a wide range of works, so a more detailed description of these programs will be placed in separate chapters. In them we will consider the structure of the future program, the necessary functions and classes.

The full working capacity of the machine requires control firmware. Its tasks include receiving information from a computer (from the machine control program), moving the laser to a position, and, in fact, burning a pixel if necessary.

The project considers engraving raster images. Not all images can be engraved on the machine equally well. The reason is the various image settings. 
Suppose there is a two-bit image, it contains only black and white pixels, which is optimal for engraving. Such images are excellent on the surface.

However, most of the images that users would like to engrave are in color or grayscale, which greatly complicates the engraving operation. Therefore, for such cases, it is necessary to create a tool that allows you to process images for engraving.

Various graphic editors use many image processing methods, but they do not always fit the parameters of a laser engraver, and some methods are completely absent.

\section{SUMMARY}

In this case, a large number of algorithms may be suitable as image processing methods, because image processing is a complex and ambiguous thing. The main criterion in this case is readability during engraving. It has already been said that two-bit images have the best result, so the optimal solution would be to maximally approximate the processing result to a similar form and without strong distortions relative to the original.

At the same time, some processing algorithms will be designed for intermediate work or superimposed on each other to enhance the effect.

\section{CONCLUSIONS}

The work has been fully completed: the laser machine implements the functionality of image reception with subsequent printing on the material, and the image processing program has sufficient functionality to prepare various images for printing.

Due to the uniqueness of the application of edge detection algorithms in this area and their sufficient practicality, the project has value and relevance in laser engraving.

Further project prospects include improving the speed of the laser machine, adding new functionality to the image processing application, and optimizing it. The laser machine can be accelerated by implementing additional laser moving algorithms. In an application for image processing, you can add multithreading to parallelize processing, optimize old algorithms.

\section{ACKNOWLEDGEMENTS}

The work is performed according to the Russian Government Program of Competitive Growth of Kazan Federal University.

\section{REFERENCES}

[1] Khaziev EL, Galiullin LA. Automation of ICE production planning. Journal of Advanced Research in Dynamical and Control Systems, 11(8), Special Issue. 2019:1771-1774.

[2] Khamadeev SA, Galiullin LA. Automation of computer technology analysis. Journal of Advanced Research in Dynamical and Control Systems. 2019;11(8):17671770.

[3] Zubkov E, Galiullin L. Automation of testing for internal combustion engine under real conditions of driving. SCOPUS-2019-11-8-SID85073411493. 2019 Jan 1.

[4] Khaziev E, Galiullin L. Algorithm for modeling the technological process of ICE production. SCOPUS2019-11-8-SID85073410283. 2019 Jan 1.

[5] Galiullin LA, Galiullin IA. Modeling of ic engines. Journal of Advanced Research in Dynamical and Control Systems. 2019;11(8): 425-431.

[6] Yarullin MG, Mingazov MR, Galiullin IA. Historical review of studies of spatial $\mathrm{nR}$ linkages. International Review of Mechanical Engineering. 2016;10(5):34856.

[7] Yarullin MG, Galiullin IA. Kinematic Research of Bricard Linkage Modifications. InAdvances in Mechanical Engineering 2016 (pp. 17-29). Springer, Cham.

[8] Khaziev EL. Control of Linear Servo Pneumatic Drive Based on Fuzzy Controller and Knowledge Base. InInternational Russian Automation Conference 2019 Sep 8 (pp. 17-25). Springer, Cham.

[9] Khaziev EL, Khaziev ML. Intelligent diagnostic system for hydraulic actuator. In2019 International Conference on Industrial Engineering, Applications and Manufacturing (ICIEAM) 2019 Mar 25 (pp. 1-6). IEEE.

[10] Galiullin IA, Galiullin LA. Fault diagnostic method for Ic engines. Journal of Advanced Research in Dynamical and Control Systems. 2019;11(8):22732279.

\section{BIOGRAPHIES OF AUTHORS}

Galiullin Lenar Ajratovich - Associate Professor, Naberezhnye Chelny Institute (branch) KFU/Higher Engineering School/Department of Information Technology and Energy Systems/Department of Information Systems, NI. Academic degrees: Candidate (technical sciences), specialty 05.13.06 - Automation and control of technological processes and production (by industry), the title of the dissertation "Automation of the technological process of diesel testing based on the fuzzy neural network method". 
International Journal of Engineering Research and Technology. ISSN 0974-3154, Volume 13, Number 11 (2020), pp. 3542-3545

(C) International Research Publication House. https://dx.doi.org/10.37624/IJERT/13.11.2020.3542-3545

Valiev Rustam Asgatovich - Head of the Department of Information Systems, Naberezhnye Chelny Institute (branch) KFU/Higher Engineering School/Department of Information Technology and Energy Systems/Department of Information Systems, NI (internal part-time). Academic degrees: Candidate of Physics and Mathematics. 